Case Report

\title{
Optic Nerve Vascular Compression in a Patient with a Tuberculum Sellae Meningioma
}

\author{
Cezar José Mizrahi, ${ }^{1}$ Samuel Moscovici, ${ }^{1}$ Shlomo Dotan, ${ }^{2}$ and Sergey Spektor ${ }^{1}$ \\ ${ }^{1}$ Department of Neurosurgery, Hadassah-Hebrew University Medical Center, 91120 Jerusalem, Israel \\ ${ }^{2}$ Department of Ophtalmology, Hadassah-Hebrew University Medical Center, 91120 Jerusalem, Israel \\ Correspondence should be addressed to Sergey Spektor; spektor@hadassah.org.il
}

Received 27 October 2014; Accepted 6 January 2015

Academic Editor: Alexander A. Bialasiewicz

Copyright @ 92015 Cezar José Mizrahi et al. This is an open access article distributed under the Creative Commons Attribution License, which permits unrestricted use, distribution, and reproduction in any medium, provided the original work is properly cited.

Background. Optic nerve vascular compression in patients with suprasellar tumor is a known entity but is rarely described in the literature. Case Description. We present a unique, well-documented case of optic nerve strangulation by the A1 segment of the anterior cerebral artery in a patient with a tuberculum sellae meningioma. The patient presented with pronounced progressive visual deterioration. Following surgery, there was immediate resolution of her visual deficit. Conclusion. Vascular strangulation of the optic nerve should be considered when facing progressive and/or severe visual field deterioration in patients with tumors proximal to the optic apparatus.

\section{Introduction}

It is well known that tuberculum sellae meningiomas cause progressive visual loss by optic nerve compression [1-5], usually due to mechanical compression by the tumor. We present a rare case, well documented, of severe deterioration in visual function as a result of optic nerve strangulation due to compression of the A1 branch of the anterior cerebral artery against the tumor.

\section{Case Presentation}

2.1. History and Physical Examination. This 50-year-old woman with no known background disease was referred to our Neurosurgery Department for progressive deterioration of visual function in her left eye of 3-4 months duration. Serial visual field examinations with stimulus $\mathrm{V}$ showed loss of three quadrants in the left eye, with only the superonasal quadrant showing a good degree of preservation (Figure 1). The right visual field was full, suggesting left optic neuropathy. T1-weighted gadolinium-enhanced MRI revealed a tuberculum sellae meningioma measuring approximately $1.7 \mathrm{~cm} \times 1.9 \mathrm{~cm} \times 1.3 \mathrm{~cm}$ (Figure 2).
2.2. Surgical Procedure. The patient underwent a left pterional craniotomy. The dura was opened and the Sylvian fissure was split, providing excellent CSF drainage and cerebral relaxation. The left frontal lobe was elevated and the tumor came into view. Inspection of the suprasellar region showed total encasement of the left optic nerve by the tumor. The tumor was internally decompressed, and the anterior communicating complex was released. Tumor pressing upon the left A1 segment of the anterior communicating artery had compressed the left optic nerve. When the tumor was removed, the nerve sagged free, exposing a clear impression of the Al segment (Figure 3). The capsule and the tumor were then removed completely, and the visual apparatus was decompressed. The patient tolerated the procedure well and was discharged 1 week later.

2.3. Followup. A full neuroophthalmologic evaluation performed 7 days after surgery revealed best-corrected visual acuity of 0.8 in both eyes with no relative afferent papillary defect. Fundal examination in the right eye showed a pink disc of normal appearance, while in the left eye there was pallor of the temporal part of the optic disc. The right visual field was normal, while in the left visual field there 


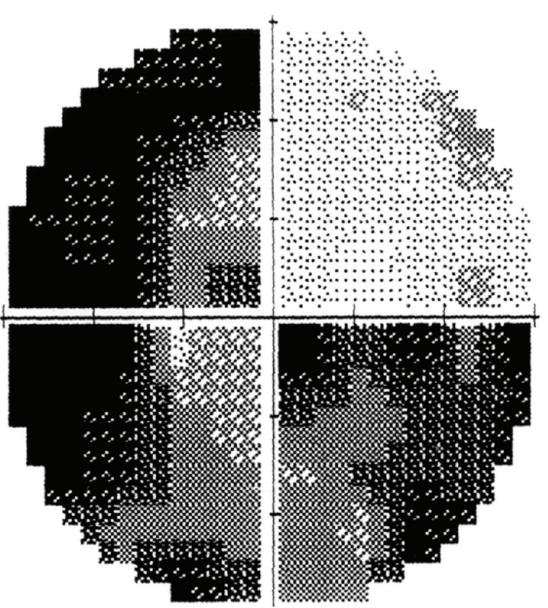

Figure 1: Preoperative left eye visual field. With stimulus V, there was loss of three quadrants with only the superonasal quadrant showing a good degree of preservation.

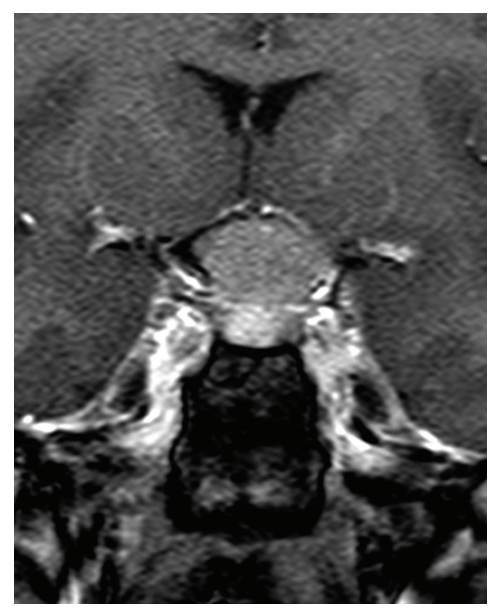

FIGURE 2: T1-weighted gadolinium-enhanced MRI revealed a tuberculum sellae meningioma measuring approximately $1.7 \mathrm{~cm} \times 1.9 \mathrm{~cm}$ $\times 1.3 \mathrm{~cm}$.

was a central scotoma and temporal depression (Figure 4). Follow-up visual field examination performed 10 months after surgery showed again a normal right visual field and a solitary paracentral scotoma in the left visual field (Figure 5). There was no evidence of residual tumor on MRI performed 6 months after surgery (Figure 6).

\section{Discussion}

We present a well-documented case of optic nerve strangulation by the A1 segment of the anterior cerebral artery in a patient a with suprasellar tumor. Once the tumor was debulked, the optic nerve sagged free presenting a clear impression of the artery, which had compressed the nerve due to pressure exerted by the meningioma on the anterior cerebral artery. Preoperative neuroophthalmic examination revealed a significant deficit in the left visual function. There was dramatic improvement immediately after surgery and

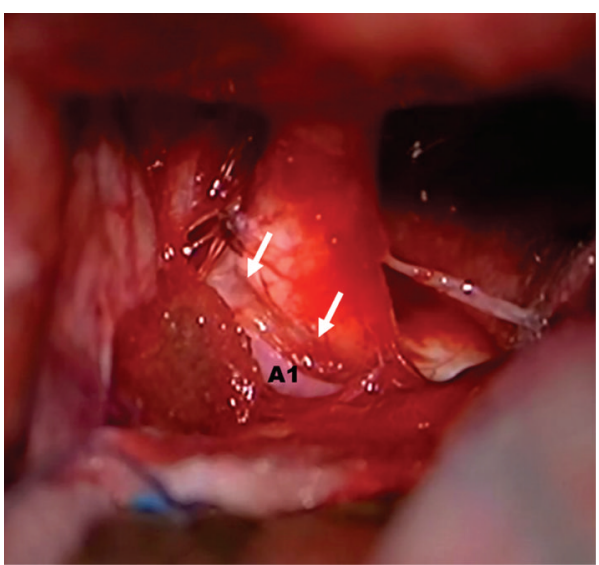

FIGURE 3: Intraoperative photograph showing a clear impression of the Al segment after tumor removal and optic nerve vascular decompression.

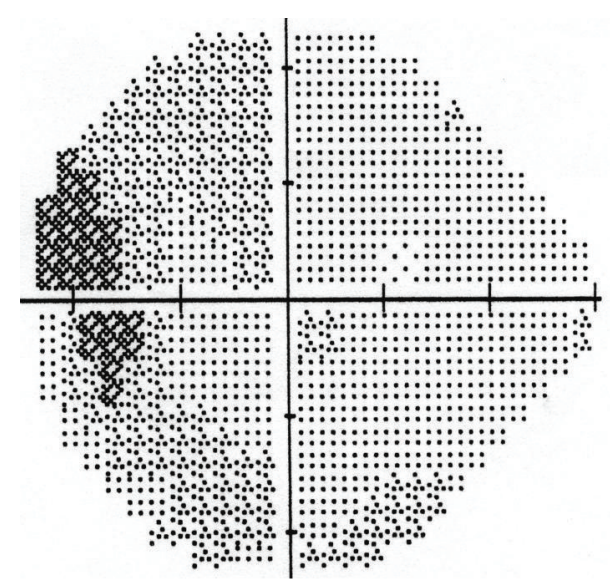

FIGURE 4: At 1-week postoperative followup, the left eye visual field examination performed with normal stimulus revealed marked improvement but residual central scotoma and temporal depression.

near complete resolution in the patient's visual field at 10month followup.

Visual loss secondary to the mechanical compression of the optic nerve by tumors, particularly by tuberculum sellae meningiomas, is well established in the literature [1$5]$, and it has been reported that vascular elements may play a significant role in the mechanism of compression [68]. Levatin [7] was a pioneer in 1961 when he described strangulation of the optic tract by the anterior cerebral artery in a patient harboring a suprasellar tumor. In 1989, Steno [8] reported compression of structures in the visual pathway by arteries of the circle of Willis within suprasellar tumors in 12 of 34 necropsies of extensive craniopharyngiomas and pituitary adenomas and in three of 109 patients operated on account of these tumors. In addition, there are several reports of compression of the optic nerve by an elongated vascular fusiform enlargement or dolichoectasia [9-12] or a nonaneurysmatic idiopathic artery compression $[13,14]$. 


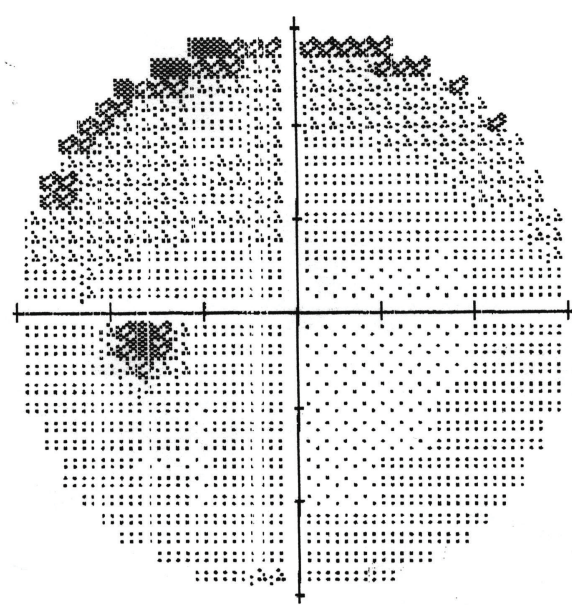

Figure 5: At 10-month postoperative followup, the left eye visual field showed a solitary paracentral scotoma.

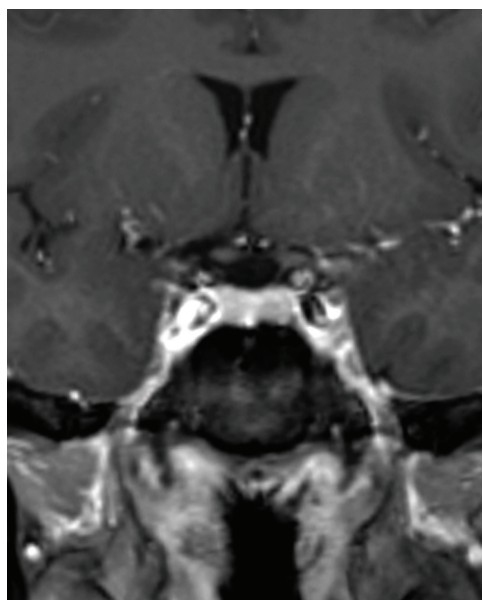

FIGURE 6: T1-weighted gadolinium-enhanced MRI performed 6 months after surgery showed no evidence of residual tumor.

We found only one paper by Bejjani et al. [6] describing vascular compression of the optic nerve due to pressure exerted by a tuberculum sellae meningioma, with intraoperative illustration of the mechanism of $\mathrm{ON}$ strangulation.

Our illustration provides further documentation that this mechanism of strangulation exists and may play role in the pathogenesis of visual loss in patients with infrachiasmatic tumors.

In summary, optic nerve vascular strangulation should be considered when facing progressive and/or severe visual field deterioration patients with tumors proximal to the optic apparatus.

\section{Conflict of Interests}

The authors have no conflict of interests to declare.

\section{References}

[1] O. Al-Mefty, A. Holoubi, A. Rifai, and J. L. Fox, "Microsurgical removal of suprasellar meningiomas," Neurosurgery, vol. 16, no. 3, pp. 364-372, 1985.

[2] B. T. Andrews and C. B. Wilson, "Supresellar meningiomas: the effect of tumor location on postoperative visual outcome," Journal of Neurosurgery, vol. 69, no. 4, pp. 523-528, 1988.

[3] R. Fahlbusch and W. Schoot, "Pterional surgery of meningiomas of the tuberculum sellae and planum sphenoidale: surgical results with special consideration of ophthalmological and endocrinological outcomes," Journal of Neurosurgery, vol. 96, no. 2, pp. 235-243, 2002.

[4] N. Margalit, A. Kesler, H. Ezer, S. Freedman, and Z. Ram, "Tuberculum and diaphragma sella meningioma-surgical technique and visual outcome in a series of 20 cases operated over a 2.5-year period," Acta Neurochirurgica, vol. 149, no. 12, pp. 1199-1204, 2007.

[5] N. S. Margalit, J. B. Lesser, J. Moche et al., "Meningiomas involving the optic nerve: technical aspects and outcomes for a series of 50 patients," Neurosurgery, vol. 53, no. 3, pp. 523-533, 2003.

[6] G. K. Bejjani, K. P. Cockerham, J. S. Kennerdell et al., "Visual field deficit caused by vascular compression from a suprasellar meningioma: case report," Neurosurgery, vol. 50, no. 5, pp.11291132, 2002.

[7] P. Levatin, "Eye findings in strangulation of the optic nerve," American Journal of Ophthalmology, vol. 51, no. 6, pp. 1308-1312, 1961.

[8] J. Steno, "Compression of structures in the visual pathway by arteries of the circle of Willis in suprasellar tumors," Ceskoslovenska Neurologie a Neurochirurgie, vol. 52, no. 2, pp. 143-147, 1989.

[9] E. V. Colapinto, M. A. Cabeen, and L. N. Johnson, "Optic nerve compression by a dolichoectatic internal carotid artery: case report," Neurosurgery, vol. 39, no. 3, pp. 604-606, 1996.

[10] K. Matsuo, S. Kobayashi, and K. Sugita, "Bitemporal hemianopsia associated with sclerosis of the intracranial carotid arteries. Case report," Journal of Neurosurgery, vol. 53, no. 4, pp. 566-569, 1980.

[11] N. McLaughlin and M. W. Bojanowski, "Microvascular decompression of the optic chiasm: case report," Journal of Neurosurgery, vol. 114, no. 3, pp. 857-860, 2011.

[12] M. G. Mitts and J. D. McQueen, "Visual loss associated with fusiform enlargement of the intracranial portion of the internal carotid artery," Journal of Neurosurgery, vol. 23, no. 1, pp. 33-37, 1965.

[13] D. M. Jacobson, "Symptomatic compression of the optic nerve by the carotid artery: clinical profile of 18 patients with 24 affected eyes identified by magnetic resonance imaging," Ophthalmology, vol. 106, no. 10, pp. 1994-2004, 1999.

[14] D. M. Jacobson, J. J. Warner, and S. K. Broste, "Optic nerve contact and compression by the carotid artery in asymptomatic patients," American Journal of Ophthalmology, vol. 123, no. 5, pp. 677-683, 1997. 


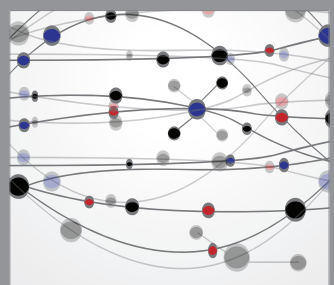

The Scientific World Journal
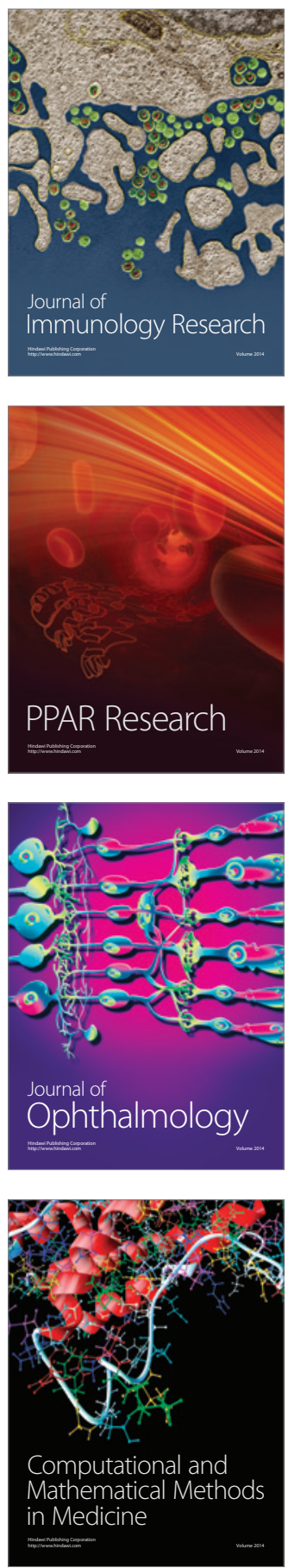

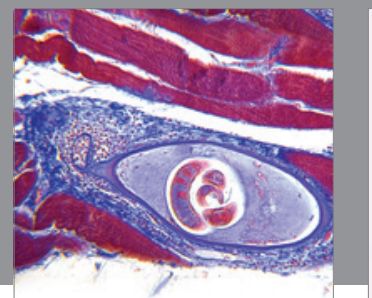

Gastroenterology

Research and Practice
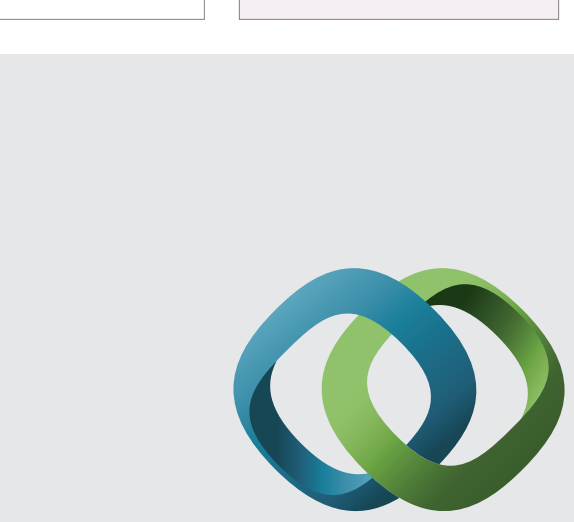

\section{Hindawi}

Submit your manuscripts at

http://www.hindawi.com
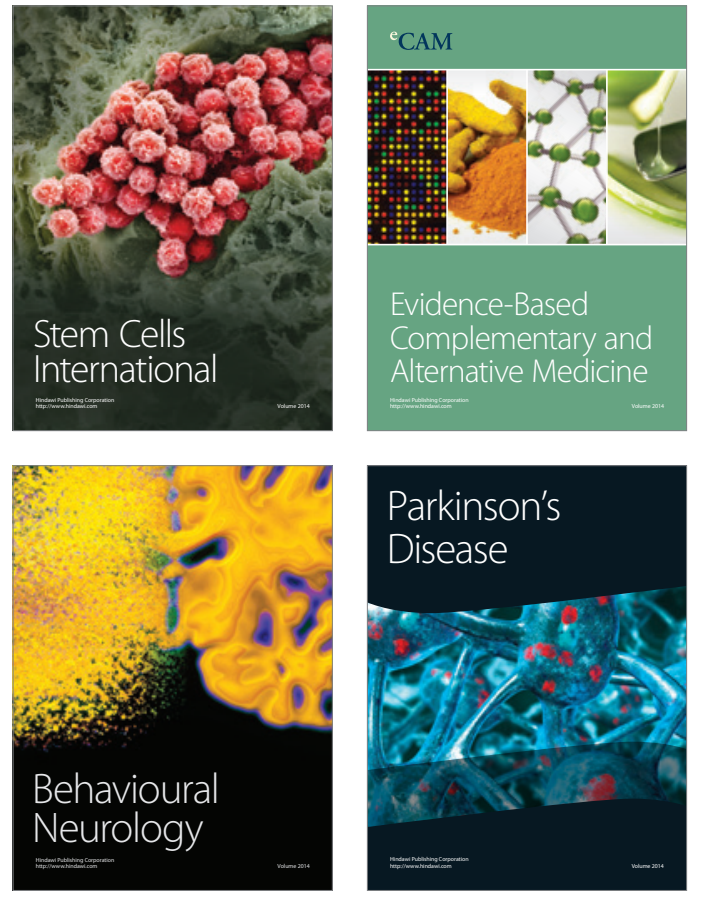
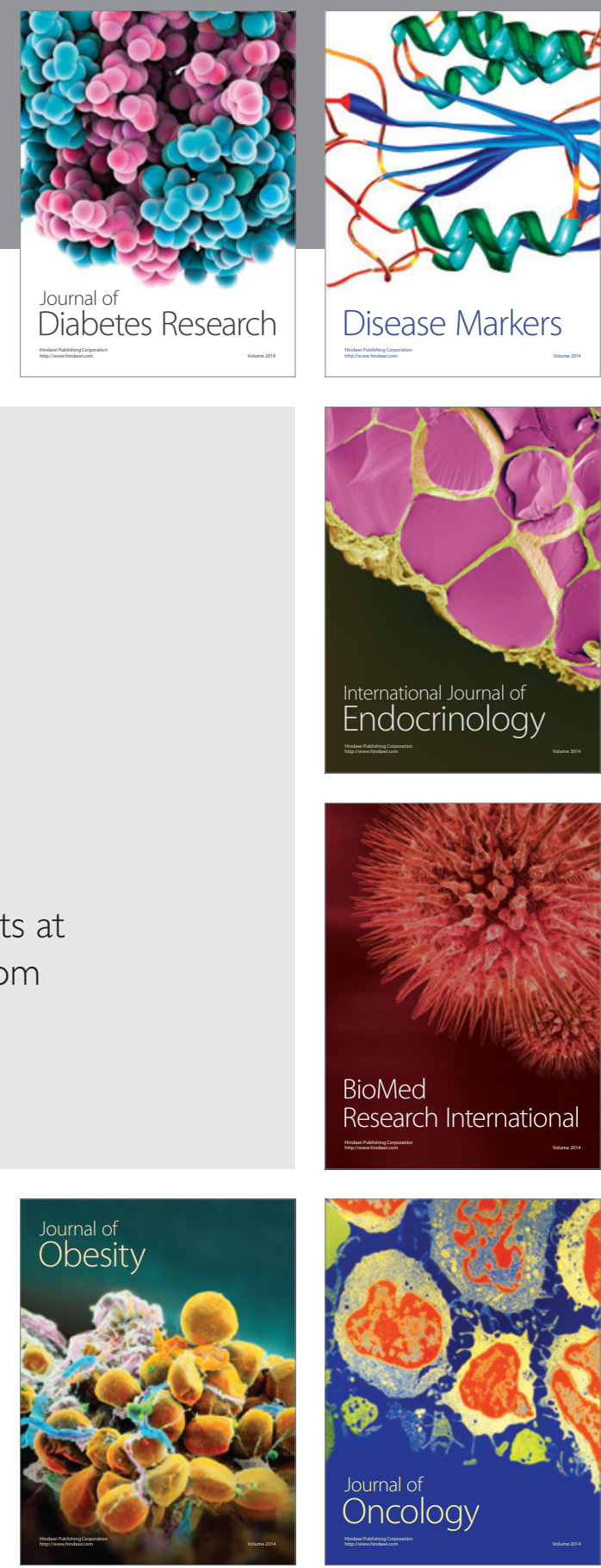

Disease Markers
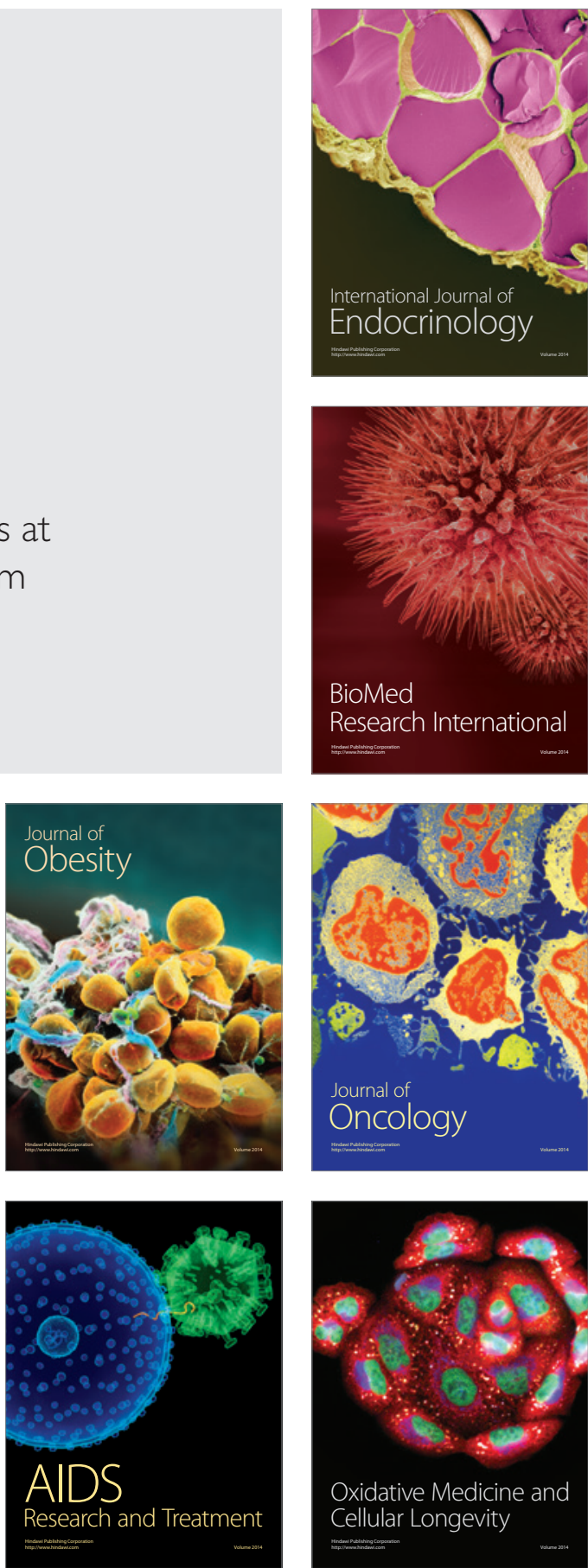